\title{
SIDDS: Simulations in developmental disabilities
}

\author{
MARCIE N. DESROCHERS \\ College of Charleston, Charleston, South Carolina \\ and \\ MATTHEW G. HILE \\ Missouri Institute of Mental Health, St. Louis, Missouri
}

\begin{abstract}
SIDDS, or simulations in developmental disabilities, is a computer system that provides students with the opportunity to acquire and practice skills in behavioral psychology. During the simulation, the student assumes the role of a psychologist whose professional duties involve the assessment and treatment of the severe problem behavior displayed by a child with a developmental handicap. Following an introduction to the use of the program, SIDDS guides the student/clinician through a series of steps involved in reducing a behavior problem. With the goal of eliminating the client's behavior problem, the student/clinician proceeds through referral, problem identification, assessment, functional hypothesis, and treatment stages. This article describes the content and structure of SIDDS and provides a glimpse of what future developments of this system will entail.
\end{abstract}

\section{REVIEW OF THE LITERATURE IN THE AREA OF EDUCATIONAL SIMULATIONS}

Simulation programs have been described as "an operating model of central features or elements of a real or proposed system, process, or environment"' (Greenblat, 1988, p. 14). They provide a dynamic and life like demonstration of the relationship between variables that affect a phenomenon. In educational settings, the use of a simulation technique allows students to make a decision and then observe the effect of that decision in a particular situation. Simulation programs are used in a wide range of teaching situations such as medicine (Bidwell, CollinsNakai, Taylor, \& Jensen, 1985; Jones \& Keith, 1983; Melnick, 1990), engineering (Stevens \& Roberts, 1983), physics (Denis, Huynen, Lebrun, Martegani, \& Mine, 1981), biology (Wedekind, 1981), sociology (Conklin, 1977), and psychology (Benedict, Butts, \& Madison, 1981; Chan, Berven, \& Lam, 1990; Fazio \& Backler, 1983; Lambert, 1987; Lambert \& Billings, 1991).

In the area of the teaching of psychology, simulations have allowed students to experience and explore complex phenomena and processes (Anderson, 1982; Bradley, 1989; Eamon, 1980; Eamon, 1982; Kissler, 1974; Lambert, Hedlund, \& Vieweg, 1990a; Lambert, Hedlund, \& Vieweg, 1990b; Petty \& Rosen, 1990; Suler, 1987). For example, one simulation program has provided students with hands-on experience in the use of a shaping technique. Shaping is a procedure used in behavioral psychol-

This work was partially supported by a faculty research and development grant from the College of Charleston. Correspondence should be addressed to M. N. Desrochers, Department of Psychology, College of Charleston, SC 29424-0001. ogy to establish new behavior by reinforcing or rewarding closer approximations to a target response (Martin \& Pear, 1992). During this simulation (Acker, Goldwater, \& Agnew, 1990), the student shapes the directional movement of a simulated animal ("Sidney Slug") by pressing a key, or delivering a reinforcer, when the animal moves toward a goal. A quiz evaluation of this program suggested that it was effective in teaching students how to employ a shaping procedure. Additionally, students rated the simulation as an enjoyable activity.

Not only are simulation programs used to illustrate psychological principles and phenomena, but they are also used to teach various clinical skills, such as the following: (1) predicting client behavior (Janikowski, Berven, Meixelsperger, \& Roedl, 1989), (2) managing client cases (Chan, Parker, Lam, Mecaskey, \& Malphurs, 1987), (3) interviewing clients (Hummel, Lichtenberg, \& Shaffer, 1975), and (4) assessing child abuse victims (MacFadden, 1989). Furthermore, simulation programs that teach complex clinical skills involving diagnosis and treatment decisions have been developed (e.g., Alpert, 1986; Hodgin, 1986; Semmel, Varnhagen, \& McCann, 1981). Evaluation of these programs is necessary to ensure the development and use of quality instructional material.

One program that has been empirically examined is called SuperShrink. This program presents case simulations to undergraduate psychology students to develop their personality analysis and diagnostic skills. In this simulation, students collect client assessment information by selecting content areas and typing in interview questions. In a recent evaluation of this program that compared computer versus booklet presentation of two simulated case studies, the results did not clearly support the use of a computer format (Lowman, 1990). In this study, contrary to an earlier study (Sussman \& Lowman, 1989) that found 
positive ratings of SuperShrink, students were required to write a paper based on the client information that they had gathered. Although the booklet version of the material was preferred by students, perhaps due to convenience, other outcome measures (i.e., student scores on an assigned written paper and a multiple choice exam) did not differ between computer versus booklet groups. This research suggests that ease of access to computers or software flexibility (e.g., software option of a printed summary report) may need to be considered when evaluating and/or designing instructional software.

In another evaluation of clinical software, four case simulations describing clients with agoraphobia, chronic headache pain, cocaine abuse, and bulimia were used to train behavior therapy strategies (Lambert, 1989). In this simulation, students select their assessment and treatment options from menus and then are presented with outcome information commonly found in natural circumstances. These programs were rated by clinical psychology and social work students as highly useful in providing knowledge of behavioral assessment and treatment strategies. In general, it seems that a simulation technique may be a potentially effective means of providing instruction in psychology, although a strong empirical base to support this claim is presently lacking.

\section{STATEMENT OF THE PROBLEM}

Clinical skills consist of a complex array of behaviors that can be difficult to teach and evaluate. When treating clinical problems, the clinician must select, interpret, and synthesize the relevant assessment information derived from many sources. Some basic clinical skills used in behavioral psychology include the following: (1) specifying the problem behavior, (2) conducting the appropriate assessments (e.g., interviews, observations, and experimental manipulation), (3) identifying the relevant assessment information, (4) analyzing graphed data depicting the client's behavior, (5) formulating a hypothesis or reason for the occurrence of the behavior, (6) selecting an appropriate treatment that addresses the specific needs of the client, and (7) evaluating the effectiveness of treatment and revising it as needed (Foxx, 1982; Hersen \& Bellack, 1985). Not only must students learn how to perform each of these skills, but they also must be able to apply them with different clients and clinical problems. Extensive and varied practice, to ensure that clinical skills transfer across varying client conditions is one of the major requirements for the development of an effective clinical repertoire (Stokes \& Osnes, 1989).

Teaching clinical skills, at least early in training, usually involves the use of textbook and lecture formats. Although initial training is traditionally conducted in this fashion, these methods may fail to convey the interacting, dynamic, and diverse nature of factors present in clinical situations. A possible solution to this problem is to conduct training in clinical settings. This option, however, is not feasible early in training because of time restrictions, cost of supervision, and potential harm (e.g., administration of ineffec- tual treatments) to the client. Thus, typically, only when a certain degree of competency in a particular clinical area is achieved by the student is practicum experience or "hands-on" training in a clinical setting offered. Although competency is usually evaluated by written examination, there is some evidence to suggest that written exams do not accurately predict professional performance (Berven $\&$ Scofield, 1980). One reason for this finding may be the difficulty involved in presenting and measuring complex clinical systems.

A potential solution to the problems involved in teaching and assessing clinical skills is to use a simulation technique that presents standardized and realistic clinical information (Zacken-Greenberg \& Neimeyer, 1986; also see Swanson \& Stillman, 1990, for a review of this model in medical training). The use of a simulation technique for training and assessing clinical skills would allow the presentation of complex clinical situations and require the student to select and integrate information generated from several sources.

\section{PROPOSED SOLUTION}

SIDDS, or simulations in developmental disabilities, is a computer system designed to provide undergraduate students with the opportunity to acquire and practice skills in the area of behavioral psychology. During the computer simulation, the student assumes the role of a behavior analyst whose professional duties involve the assessment and treatment of the severe problem behavior displayed by a child with a developmental handicap.

\section{Description of the Simulation Process}

Following an introduction to the use of the program, SIDDS guides the student/clinician through a series of steps involved in reducing a behavior problem. During the simulation, the student/clinician proceeds through referral, problem definition, assessment, functional hypothesis, and treatment stages in order to assess and treat the presenting clinical case.

Referral. Similar to what occurs in applied settings, a referral form introduces the student/clinician to the problem situation. The referral form is displayed on the computer screen and describes the behavior problem (aggression in this case), circumstances in which it occurs (school), and characteristics of the client (e.g., level of mental retardation). After a general overview of the problem, the student/clinician is asked whether he or she will accept the referral or would like to refer it to another professional (medical or other area in psychology).

Assessment. If the case is accepted, the student/clinician selects from a menu the particular behavioral assessments desired. Assessment choices include interviews, data from behavioral observations, baseline graph of the behavior, and graphs involving experimental manipulation of various conditions (e.g., demand, attention, alone, and social disapproval). The objective in this phase of the clinical process is to collect the relevant clinical information (e.g., length, severity, and duration of the be- 
havior; previous treatments; and circumstances in which the behavior occurs) required to choose an effective treatment.

A unique feature of SIDDS, in contrast to most simulation programs, is that graphs depicting the level of the simulated client's behavior during assessment and treatment phases are presented. Moreover, the amount of data collected and displayed on a graph can be controlled by the student/clinician. The student/clinician presses a key on the keyboard to "collect a data point" or presses another key to terminate the session. Control over the length of assessment and treatment phases enables the student/clinician to analyze trends and patterns in the data and decide when to conduct the next phase. For example, the student/clinician must decide whether five or six data points are sufficient to determine the influence of a particular assessment condition or treatment strategy.

Problem definition. Prior to or during the collection of assessment data, the student/clinician must clearly and completely specify the problem behavior. The behavioral definition is entered from the keyboard using a free-text format. When the entry is complete, a checklist of pertinent points (e.g., how, where, and when the behavior is to be measured; whether a naive observer could identify it) is displayed, after which modification of the definition by the student is permitted.

Functional hypothesis. The basic rationale underlying SIDDS is that, in general, treatment decisions should be based on an understanding of the variables contributing to the occurrence of the problem behavior. The behavioral literature in the mental retardation/developmental disability area suggests that there are different categories of variables that influence severe problem behaviors (Cipani, 1989; Gardner, Cole, Davidson, \& Karan, 1986; Mace, Lalli, \& Lalli, 1991). For example, the problem behavior may be due to antecedent stimuli in the environment (e.g., demands or instruction), attention or tangible consequences delivered after the behavior, escape or avoidance from unpleasant situations, physiological under- or overarousal, or physical reasons (e.g., PMS, headaches, and allergies; O’Neill, Horner, Albin, Storey, \& Sprague, 1990; Taylor \& Carr, 1992a, 1992b).

Furthermore, consideration of these causal variables is important for the selection of an effective treatment (Hile \& Desrochers, in press; Repp, Felce, \& Barton, 1988; Steege, Wacker, Berg, Cigrand, \& Cooper, 1989; Wacker et al., 1990). For example, one case simulation may involve a client engaging in aggressive behavior because he or she receives attention from the teacher and other students in the classroom (i.e., positive reinforcement). Another case simulation may involve a client who avoids difficult schoolwork because he or she is removed from the classroom immediately after an aggressive outburst (i.e., escape conditioning). Treatment will vary depending on the functional hypothesis. In the first situation, treatment may involve providing positive reinforcement for other desirable behavior, whereas treatment in the sec- ond situation may involve decreasing the difficulty of the task and providing breaks after brief periods of work.

Following the assessment stage in the simulation, the student/clinician can choose to confer with another psychologist regarding the analysis of the cause of the behavior. Textually presented advice to consider certain assessments or confirmation of the student/clinician's functional hypothesis selection is provided as feedback.

Treatment. When the student/clinician has identified the variables contributing to the occurrence of the behavior, the next step is to choose a potentially effective treatment. The student/clinician selects one general treatment category from a menu (e.g., skill training, reinforcement-based, environmental change, or consequences for target), from which specific procedural options (e.g., communication, relaxation, or self-control training for the area of skill training) can be selected. When the student/clinician has chosen the desired procedure or treatment package, the client's behavior can be graphed and the effect of treatment evaluated by the student/clinician. The most effective treatment for a specific case is based on information gathered from a review of empirical research conducted in this area (e.g., Hile \& Desrochers, in press).

\section{Program Features}

Effective instructional techniques and computer-friendly features have been incorporated into the design of the software (see Hannafin \& Hooper, 1989, for a description of some of these features). One notable feature of SIDDS is the use of hypertext terminology. Hypertext allows the student to select highlighted material on the computer screen and access windows containing additional information on the topic being addressed (Jonassen, 1989). In SIDDS, hypertext terms are used to allow further clarification of assessment and treatment options, and to define behavioral terminology found throughout the simulation. Another instructional feature is the use of a "hints" button located on many screens that, when selected, presents information on "what to do next" for inexperienced student/clinicians. Present on many screens is a reference button that provides student/clinicians with a complete reference citation, if desired. Another item displayed on most screens is a "notepad" option that allows student/clinicians to access their own files, in which they can type in notes and observations during the simulation. In addition, student/ clinicians are able to print graphs or any other information displayed on the screen, and data on the students' responses is stored to allow modification of the program.

\section{Software and Hardware Requirements}

The software used to create SIDDS is KnowledgePro (1987), a high-level programming language. The hardware needed to operate this simulation includes any IBMPC, XT, AT, or compatible computer with hard disk, color monitor, and printer. 


\section{ADVANTAGES AND DISADVANTAGES OVER ALTERNATIVE APPROACHES}

Traditionally, clinical skills have been taught through textbook, lecture, or practicum format. Supplementing these modes of teaching with the use of a simulation technique may enhance students' acquisition of clinical skills. There are many advantages to using computer simulations as a teaching tool, such as the following: (1) students are able to experience events without risk of harm or damage to themselves or others, (2) unique situations can be explored, (3) it is a timesaving device that allows rapid display of complex phenomena, (4) effective teaching strategies can be easily programmed (e.g., immediate feedback, learner control, and individualized student participation), and (5) students' responses may be readily recorded and compared (Flynn, 1990; Jelovsek, Catanzarite, Price, \& Stull, 1989; Jolly, 1982; Jones \& Keith, 1983; Kinzle, 1990; Miller, 1984).

A major disadvantage of simulation programs is that it is not feasible to address the entire range of variables that could possibly influence a client's behavior. That is, only a sample of the variables involved in an actual clinical case can be represented. Another limitation of the simulation is that visual observation of the behavior, a major means of determining possible causes of the client's problem behavior in actual clinical settings, is not presently a feature of this program. Thus, it should be emphasized that a simulation program cannot substitute for hands-on experience in an applied situation.

\section{SUGGESTIONS FOR GENERALIZATION AND APPLICATION}

SIDDS may be used as a supplemental instructional tool to facilitate the student's application of clinical principles and procedures to problem situations typically found in clinical settings. It is designed for use in educational courses in which the principles and procedures of behavior modification are taught. SIDDS may also be used to provide staff who work in group homes or institutional settings for the developmentally handicapped with training in clinical skills. Furthermore, SIDDS may provide a means by which the clinical skills of job applicants or current staff can be objectively evaluated.

SIDDS can be developed for use with other target populations. Additional computer applications that train people in various skills can be easily developed by modifying SIDDS' content. For example, it may be a suitable tool for use in training parents in child management skills.

\section{POSSIBLE FURTHER DEVELOPMENT AND DIRECTIONS FOR FUTURE WORK}

In addition to expanding the number of client cases presented by SIDDS, future work on SIDDS will consist of researching the effectiveness of the simulation in teaching assessment and treatment skills, developing a comprehensive computer-aided instruction (CAI) package, and creating a multimedia environment. Research is necessary to determine the instructional effectiveness of this and other case simulations that are developed. Topics to be studied include the following: (1) determining whether the simulation teaches the student clinical skills, (2) comparing the effect of use of the simulation to other more traditional forms of instruction, and (3) identifying the optimal number of client cases necessary for the student to transfer skills to new problems or situations.

When the simulation is completed, a comprehensive and individualized program of instruction will need to be developed. Briefly, this CAI package will consist of the following components: (1) a quiz to evaluate the student's present level of skill, (2) a tutorial to remediate deficiencies in knowledge, and (3) a simulation to provide the student with the opportunity to apply conceptual skills to a semi-realistic situation.

Another development of this system will involve incorporating into the simulation program visual displays (videodisk or videotape) that depict the client engaging in the problem behavior in the natural environment. The student/clinician would be required to conduct behavioral observations, and his or her data would be compared, online, with a standard for calibration purposes.

A preliminary evaluation of SIDDS has been conducted. SIDDS has been evaluated by four professors of psychology. Using a 7-point Likert scale, the ratings indicated that, overall, it is slightly easy to learn how to operate and quite easy to use. In terms of instructional value, SIDDS was perceived to be quite useful for training students in behavioral assessment and treatment skills. Compared with traditional instructional formats (e.g., textbook and lecture), SIDDS was considered by the evaluators to be quite useful. Although a simulation technique provides a potentially effective supplement to a clinical training situation, continual research during the development process is necessary to ensure that a quality product is created. It is hoped that, with the necessary evaluation and modification, SIDDS will prove to be a useful tool by which clinical skills can be developed and sharpened.

\section{REFERENCES}

Acker, L. E., Goldwater, B. C., \& Agnew, J. L. (1990). Sidney Slug: A computer simulation for teaching shaping without an animal laboratory. Teaching of Psychology, 17, 130-132.

AlPERT, D. (1986). A preliminary investigation of computer-enhanced counselor training. Computers in Human Behavior, 2, 63-70.

Anderson, D. E. (1982). Computer simulations in the psychology laboratory. Simulation \& Games, 13, 13-36.

Benedict, J. O., Butts, B. D., \& Madison, J. (1981). Computer simulation or real experimentation: Is one better for teaching experimental design? Teaching of Psychology, 8, 35-38.

Berven, N. L., \& Scofield, M. E. (1980). Evaluation of professional competence through standardized simulations: A review. Rehabilita tion Counseling Bulletin, 24, 178-202. 
Bidwell, C. M., Collins-Nakai, R. L., Taylor, W. C., \& Jensen, W. A. (1985). Multidisciplinary team production of computer-based simulations to teach pediatrics. Joumal of Medical Education, 60 , $397-403$.

BradLey, D. R. (1989). A general purpose simulation program for statistics and research methods. Advances in Social Science \& Computers, 1, 145-186.

Chan, F., Berven, N. L., \& Lam, C. S. (1990). Computer-based, casemanagement simulations in the training of rehabilitation counselors. Rehabilitation Counseling Bulletin, 33, 212-228.

Chan, F., Parker, H. J., Lam, C. S., Mecaskey, C., \& Malphurs, L. (1987). Computer case management simulations: Applications in rehabilitation education. Rehabilitation Counseling Bulletin, 30, 210-217.

CIPANI, E. (ED.) (1989). The treatment of severe behavior disorders: Behavior analysis approaches. Washington, DC: American Association on Mental Retardation.

ConkLin, G. H. (1977, June). Experimental simulation in introductory sociology: Modifying EXPER-SIM to meet the needs of beginners. Paper presented at the Conference on Computers in the Undergraduate Curricula, East Lansing, MI.

Denis, J. P., Huynen, A. M., Lebrun, M., Martegani, A., \& MINE, P. (1981). Simulation and learning by discovery. In D. Wildenberg (Ed.), Computer simulation in university teaching (pp. 3541). Amsterdam: North-Holland.

EAMON, D. B. (1980). LABSIM: A data-driven simulation program for instruction in research design and statistics. Behavior Research Methods \& Instrumentation, 12, 160-164.

EAmon, D. B. (1982). CEDATS: A cognitive experimental design and testing system. Behavior Research Methods \& Instrumentation, 14, 142-145.

Fazio, R. H., \& Backler, M. H. (1983). Computer lessons for a social psychology research methods course. Behavior Research Methods \& Instrumentation, 15, 135-137.

FLYNN, J. P. (1990). Using the computer to teach and learn social policy: A report from the classroom and the field. Computers in Human Ser vices, 7, 199-209.

Foxx, R. M. (1982). Decreasing behaviors of severely retarded and autistic persons. Champaign, IL: Research Press.

Gardner, W. I., Cole, C. L., Davidson, D. P., \&aran, O. C. (1986). Reducing aggression in individuals with developmental disabilities: An expanded stimulus control, assessment, and intervention model. Education \& Training of the Mentally Retarded, 21, 3-12.

Greenblat, C. S. (1988). Designing games and simulations. Newbury Park, CA: Sage Publications.

HANNAFin, M. J., \& HoOPER, S. (1989). An integrated framework for CBI screen design and layout. Computers in Human Behavior, 5 , $155-165$.

Hersen, M., \& Bellack, A. S. (EDs.) (1985). Behavioral assessment: A practical handbook. New York: Pergamon Press.

Hile, M. G., \& Desrochers, M. N. (in press). The effect of functional analysis on treatment selection for aggressive behavior. Research in Developmental Disabilities.

HoDGIN, J. D. (1986). Microcomputers, interactive videodisks, and psychodynamic simulations. Southern Medical Journal, 79, 451-454.

Hummel, T. J., Lichtenberg, J. W., \& SHAfFer, W. F. (1975). CLIENT 1: A computer program which simulates client behavior in an initial interview. Journal of Counseling Psychology, 22, 164-169.

Janikowski, T. P., Berven, N. L., MeixelsPerger, M. K., \& Roedl, K. E. (1989). A computer-based case simulation to assess skill in predicting client behavior. Rehabilitation \& Counseling Bulletin, 33, 127-139.

Jelovsek, F. R., Catanzarite, V. A., Price, R. D., \& Stuli, R. E. (1989). Application of teaching and learning principles to computeraided instruction. CAI in Medicine, 6, 267-273.

Jolly, B. (1982). A review of issues in live patient simulation. Programmed Learning \& Education Technology, 9, 108-114.

JoNASSEN, D. H. (1989). Functions, applications, and design guidelines for multiple window environments. Computers in Human Behavior, $5,185-194$.
Jones. G. L. \& Kerth. K. D. (1983). Computer clinical simulations in health sciences. Joumal of Computer-Based Instruction, 9. 108-114.

KINZLE, M. B. (1990). Requirements and benefits of effective interactive instruction: Learner control, self-regulation, and continuing motivation. Educational Technology Research \& Development, 38, $1-21$

KisSLER, G. R. (1974). Evaluation of computer-based laboratory simulation models to teach scientific research strategies. Behavior Research Methods \& Instrumentation, 6, 124-126.

KNOWLEDGEPro (1987). Nassau. NY: Knowledge Garden, Inc.

LAMBERT, M. E. (1987). A computer simulation for behavior therapy training. Journal of Behavior Therapy \& Experimental Psychiarry, 18, 245-248.

LAMBERT, M. E. (1989). Using computer simulations in behavior therapy training. Computers in Human Services, 5(3-4), 1-12.

LAMBERT, M. E., \& Billings, M. (1991). Harnessing computer technology for behavioral therapy training and research. In $M$. Hersen, R. M. Eisler, \& P. M. Miller (Eds.), Progress in behavior modification (Vol. 27, 86-103). Newbury Park, CA: Sage Publications.

Lambert, M. E., Hedlund, J. L., \& Vieweg, B. W. (1990a). Computer simulations in mental health education: Current status. Computers in Human Services, 7, 211-229.

Lambert, M. E., Hedlund, J. L., \& Vieweg, B. W. (1990b). Computer simulations in mental health education: Two illustrative projects. Computers in Human Services, 7, 231-245.

LowmAN, J. (1990). Failure of laboratory evaluation of CAI to generalize to classroom settings: The SuperShrink interview simulation. Behavior Research Methods, Instruments, \& Computers, 22, 429-432.

Mace, F. C., Lalli, J. S., \& Lalli, E. P. (1991). Functional analysis and treatment of aberrant behavior. Research in Developmental Disabilities, 12, 155-180.

MacFadDEN, R. J. (1989). Sexual abuse assessment training: Developing CAI in child welfare. Computers in Human Services, 5(3-4), 29-41.

Martin, G., \& Pear, J. J. (1992). Behavior modification: What it is and how to do it (4th ed.). Englewood Cliffs, NJ: Prentice-Hall.

MELnick, D. E. (1990). Computer-based clinical simulation. Evaluation and the Health Professions, 13, 104-120.

Miller, M. D. (1984). The use of simulations in training programs: A review. Educational Technology, 24, 39-42.

O'Neill, R. E., Horner, R. H., Albin, R. W., Storey, K., \& SPRAGUE, J. R. (1990). Functional analysis of problem behavior: $A$ practical assessment guide. Sycamore, IL: Sycamore Publishing Co.

PetTy, L. C., \& Rosen, E. F. (1990). Increase in mastery levels using a computer-based tutorial/simulation in experimental psychology. Behavior Research Methods, Instruments, \& Computers, 22, 216218.

Repp, A. C., Felce, D., \& Barton, L. E. (1988). Basing the treatment of stereotypic and self-injurious behaviors on hypotheses of their causes. Journal of Applied Behavior Analysis, 21, 281-289.

Semmel, M. I., Varnhagen, S., \& McCann, S. (1981). MICROGAMES: An application of microcomputers for training personnel who work with handicapped children. Teacher Education \& Special Education, 4, 27-33.

Steege, M. W., Wacker, D. P., Berg, W. K., Cigrand, K. K., \& COOPER, L. J. (1989). The use of behavioral assessment to prescribe and evaluate treatments for severely handicapped children. Journal of Applied Behavior Analysis, 22, 23-33.

STEVENS, A., \& RoBerts, B. (1983). Quantitative and qualitative simulation in computer based training. Journal of Computer-Based Instrumentation, 10, 16-19.

STOKES, T. F., \& OSNES, P. G. (1989). An operant pursuit of generalization. Behavior Therapy, 20, 337-355.

Suler, J. R. (1987). Computer-simulated psychotherapy as an aid in teaching clinical psychology. Teaching of Psychology, 14, 37-39.

SUSSMAN, D., \& LowmAN, J. (1989). Hard-copy versus computer presentation of the SuperShrink interview simulation. Teaching of Psychology, 16, 227-230.

Swanson, D. B., \& Stillman, P. L. (1990). Use of standardized pa- 
tients for teaching and assessing clinical skills. Evaluation and the Health Professions, 13, 79-103.

TAYLOR, J. C., \& CARR, E. G. (1992a). Severe problem behaviors related to social interaction: 1. Attention seeking and social avoidance. Behavior Modification, 16, 305-335.

TAYlor, J. C., \& CARR, E. G. (1992b). Severe problem behaviors re lated to social interaction: 2. A systems analysis. Behavior Modification, 16, 336-371.

W Acker, D. P., Steege, M. W., Northup, J., Sasso, G., Berg, W. Reimers, T., Cooper, L., Cigrand, K., \& Donn, L. (1990). A com- ponent analysis of functional communication training across three topographies of severe behavior problems. Journal of Applied Behavior Analysis, 23, 417-429.

WEDEKIND, J. P. (1981). The instructional use of computer simulation in the teaching of biology: Three examples. In D. Wildenberg (Ed.), Computer simulation in university teaching (pp. 223-235). Amsterdam: North-Holland.

Zacken-GreenberG, F., \& NeImeyer, G. J. (1986). The impact of structural family therapy training on conceptual and executive therapy skills. Family Process, 25, 599-608. 